\title{
Impact of cereal rotation strategies on soil inoculum concentrations and wheat take-all
}

\author{
R.F. van Toor $^{1}$, S.L. Bithell ${ }^{1}$, S.F. Chng ${ }^{1}$, A. McKay² and M.G. Cromey ${ }^{1}$ \\ ${ }^{1}$ The New Zealand Institute for Plant E Food Research Limited, Private Bag 4704, \\ Christchurch 8140, New Zealand \\ ${ }^{2}$ South Australian Research and Development Institute, GPO 397, Adelaide 5001, \\ South Australia \\ Corresponding author: matthew.cromey@plantandfood.co.nz
}

\begin{abstract}
The fungus Gaeumannomyces graminis var. tritici ( $G g t)$ causes take-all in cereals and survives saprophytically on crop debris during the intercrop period. Commercial wheat fields with different crop rotations on 10 farms in the South Island of New Zealand were monitored over 6 years for changes in Ggt inoculum concentrations and take-all severity. Take-all severity in wheat varied greatly among crop rotations across the farms, with aboveground symptoms seldom visible on some farms and common on others. Take-all severity was reduced by maintaining a low frequency of host crops in the rotation. Ggt was detected in soil from all farms. Soil inoculum concentrations were reduced proportional to the length of non-host break crops. While barley, triticale and rye are less susceptible than wheat to take-all, they can lead to high post-harvest inoculum concentrations.
\end{abstract}

Keywords soil-borne disease, cereals, Gaeumannomyces graminis var. tritici, crop rotation.

\section{INTRODUCTION}

Take-all, caused by the fungus Gaeumannomyces graminis var. tritici $(G g t)$, is the most important root disease of wheat worldwide (Hornby 1998; Cook 2003). The fungus infects susceptible plants, resulting in blackened roots, stunting of the plant and its premature death (Cook 2003).

Between crops, Ggt survives saprophytically on crop debris, and its concentration declines as the crop debris decays (Hornby 1981; Bithell et al. 2009). Soil moisture affects the rate of inoculum decline; Ggt can survive for long periods in dry environments (MacNish \& Dodman 1973), but inoculum decline is more rapid where warm wet conditions follow harvest (Cook 2003). In New Zealand, postharvest Ggt concentrations in the soil following second wheat crops declined by $78 \%$ over the 4 months following harvest (Bithell et al. 2009). The amount of inoculum present in the soil at crop establishment affects the extent of primary infection of a susceptible host cereal such as wheat (Bailey \& Gilligan 1999). Presowing soil Ggt concentrations of $<6 \mathrm{pg}$ and $>80 \mathrm{pg} G g t$ DNA/g soil are associated with low and high risk, respectively, of take-all in second wheat crops under environmental conditions that favour disease development (Ophel-Keller et al. 2008; Bithell et al. 2012).

Non-host break crops provide an important means to reduce Ggt concentrations (Hornby 1981). Thus crop rotation incorporating non- 
host crops is an effective method to manage take-all (Yarham 1981). A good understanding of the effects of host and non-host crops on Ggt concentrations is a key to better management of take-all. This paper summarises the results of a 6-year study to monitor effects of different crop sequences on take-all severity and Ggt concentrations in soil in commercial wheat fields on 10 farms in the South Island of New Zealand where take-all is common (Cromey et al. 2006).

\section{MATERIALS AND METHODS Field sites}

This study surveyed 87 commercial fields between 2003 and 2009 on 10 farms in the Canterbury and Southland regions of New Zealand, where wheat is a substantial part of the cropping sequence. Crop sequence information was collected for 3 years prior to the start of the survey. Farms A, $\mathrm{C}, \mathrm{E}$ and $\mathrm{J}$ are in Mid-Canterbury; farms D, H, I, $\mathrm{L}$ and $\mathrm{M}$ are in South Canterbury and farm $\mathrm{B}$ is in Southland. Crops in farms A, J, D, H and M were irrigated; crops in the other farms were not. On each farm, between 6 and 14 fields were surveyed, providing a total of 291 wheat crops in the study. When wheat crops are grown consecutively in a field, they are named according to their position in the sequence. For example, two or three successive wheat crops in a field are referred to as second and third wheat crops respectively, while the first wheat following a non-host break crop is referred to as a first wheat crop (Bateman et al. 2004). In the present study, of the 291 wheat crops over the 6 years, 14 followed barley, rye or triticale. Although they do not normally express take-all symptoms, these crops are hosts of Ggt (Bithell et al. 2011), and results indicated they support inoculum build-up similar to that of wheat, so were regarded as part of the wheat sequence.

\section{Soil tests}

Pre-sowing soil samples were collected from each field from late February to April from 2003 to 2008. The soil sample was a composite of 50 cores ( $10 \mathrm{~mm}$ diameter, $100 \mathrm{~mm}$ depth) collected as duplicate cores from 25 positions approximately $10 \mathrm{~m}$ apart on a $\mathrm{W}$ pattern from an area approximately $65 \times 100 \mathrm{~m}$. The sample area was identified by GPS coordinates. When stubble was present from the previous crop, one core was taken between stubble rows and one within the row. Following collection, the samples were dried and sent to the Root Disease Testing Service (SARDI, Adelaide, Australia) for analysis. Results were supplied as pg Ggt DNA/g soil. Concentrations of G. graminis var. avenae were also supplied for some fields.

\section{Take-all measurements in wheat crops}

Approximately 100 plants were collected from each field at early grain fill stage in cereal crops during December from 2003-2008 for assessment. The root systems were washed and assessed for take-all on a scale of $0-4 \quad(0=$ no take-all; $1=1-10 \%$ of the root system affected; $2=11-30 \% ; 3=31-60 \% ; 4=61-100 \%)$. The proportion of plants in each category was used to derive a take-all index (TAI), calculated as $(0 \mathrm{a}+10 \mathrm{~b}+30 \mathrm{c}+60 \mathrm{~d}+100 \mathrm{e}) / \mathrm{T}$ where $\mathrm{a}, \mathrm{b}, \mathrm{c}, \mathrm{d}$ and $e$ are the number of plants in each infection category and $\mathrm{T}=$ total number of plants $(\mathrm{a}+\mathrm{b}+$ $c+d+e)$ (Hornby \& Beale 2000). This index has a maximum value of 100 . The incidence of takeall infection was calculated as the percentage of infected plants in each field sample.

\section{RESULTS}

\section{Host crops}

Crop rotations differed more between farms, than between fields on individual farms. Host crops of Ggt (wheat, barley, triticale and rye) were sown at least twice in all 87 fields during the 10 years and averaged $57 \%$ of the rotation on the 10 farms (Figure 1a). The host crops comprised $80 \%$ wheat, $17 \%$ barley, and $3 \%$ triticale or rye. Ryegrass was the most common break crop, comprising $18 \%$ of all crops grown in the rotations, including host crops. Clover was more common than ryegrass on two farms. There were differences between farms in the proportions of host crops: three farms had $<40 \%$ and three had more than $60 \%$. While wheat was the most common host, barley represented $>40 \%$ of the host crops on two farms. 
a.

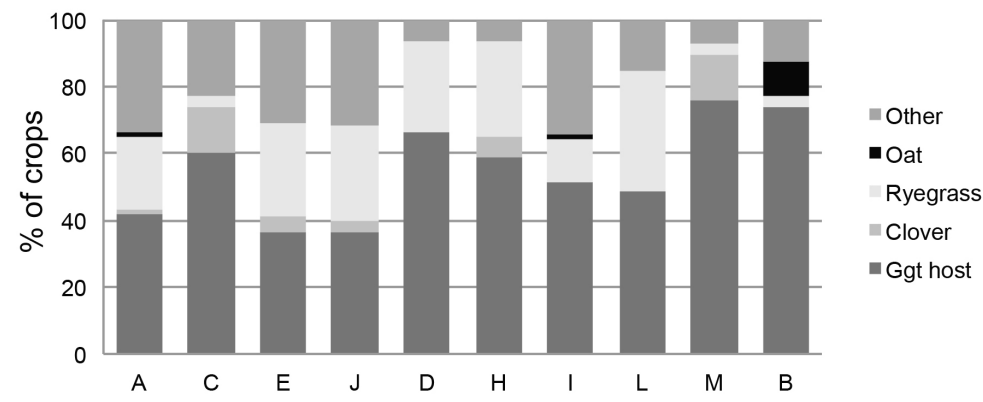

b.

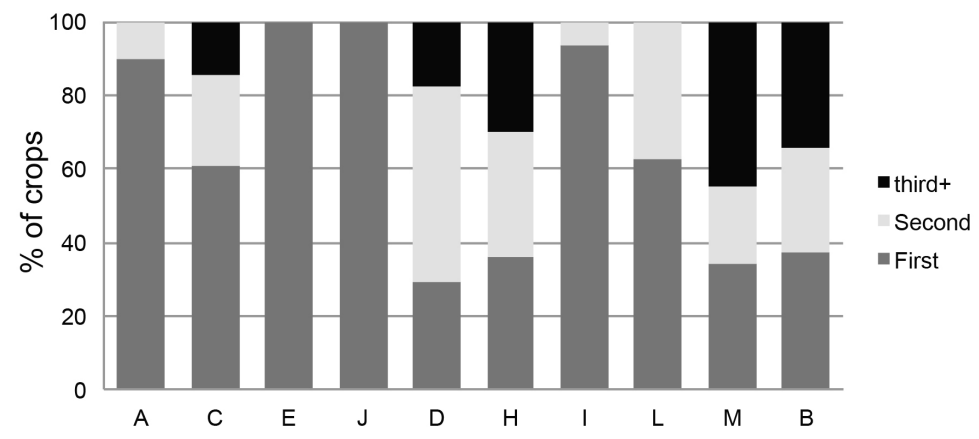

Figure 1 Proportions of (a) host (wheat, barley, triticale and rye) and non-host crops on 10 New Zealand farms (AM) between 1999 and 2008 and (b) proportions of wheat crops between 2002 and 2008 that followed a break crop ('first'), or were sown later as 'second' or 'third plus' wheat in a sequence of host crops.

Of the wheat crops in 2002-08, 53\%, 25\% and $22 \%$ were first, second and third or more host crops, respectively (Figure 1b). There were a few fourth to ninth wheat crops. Farms differed substantially in the frequency of second host crops: two produced only first wheat crops, while on three farms, first wheat crops represented less than $50 \%$ of wheat crops. More than four consecutive host crops were sown on three farms.

\section{Soil Ggt concentrations and take-all}

The general pattern across the 87 fields was for soil Ggt concentrations following a break crop to be $<6$ pg and take-all severity to be low in the first wheat crop following the break crop. Soil Ggt concentrations and take-all severity tended to increase with consecutive host crops, but some declined after successive host crops.

Median soil Ggt concentrations were lowest after a non-host crop, increased 15-fold following a first host crop, and reached a maximum after the second host crop (Figure 2a). There were also consistent differences between farms following first, second and third consecutive host crops. Ggt concentrations were consistently high on farm D and consistently low on farm E. Median Ggt concentrations were 9 pg and 146 pg, and 14 and 533 pg after the first and second host crops on farms E and A respectively.

Median take-all severity was also low in first wheat crops and reached a maximum in second wheat crops (Figure 2b). There were also differences between farms, with median take-all severity in second wheat crops being high on farm $\mathrm{D}$ and low on farm $\mathrm{B}$.

The proportions of fields in different presowing Ggt risk categories ( $<6$ pg being low risk and $>80 \mathrm{pg}$ being high risk to take-all) varied between farms and host crop sequence (Figure 3). Before sowing of a first host crop, most Ggt concentrations were low, with five of the 10 farms having concentrations $<6 \mathrm{pg}$ in most of their fields. However, two farms had $>80 \%$ of fields with $G g t$ concentrations $>6 \mathrm{pg}$ before sowing 
a first wheat crop and some fields had $>80 \mathrm{pg}$ before sowing a first wheat crop (Figure 3a).

Take-all was seldom severe in first wheat crops, with six farms having no fields with a TAI $>20$ (Figure 3c), and seven with none at TAI $>30$. However, of the only two first wheat crops of farm $\mathrm{D}$, one had a TAI $>20$ and the other a TAI $>30$.

Following a first host crop, most fields had Ggt concentrations $>6 \mathrm{pg}$, although there were differences between farms (Figure 3e). In six of the 10 farms, at least half the fields had Ggt $>80 \mathrm{pg}$, but two farms ( $\mathrm{C}$ and $\mathrm{E}$ ) had fewer than half the fields with Ggt concentrations $>40 \mathrm{pg}$.

Before sowing a second host crop, however, soil inoculum concentrations were high. Six farms had 40 to $60 \%$ of fields with Ggt concentrations
$>80 \mathrm{pg}$, although on one farm (B) most fields were $<6$ pg (Figure $3 \mathrm{~b}$ ). On two farms, barley rather than wheat was sown as the second host crop. On two other farms, a second wheat was sown only once and in each case the TAI was $>20$. On the remaining six farms, four had TAI $>20$ in most second wheat fields and two farms had $<40 \%$ with TAI $>20$ (Figure 3d). Following harvest of the second host crop, Ggt concentrations were $>80$ pg in most fields (Figure 3f).

There were differences in Ggt concentrations between farms and between wheat in different phases of the cropping sequence (Table 1). Most fields with pre-sowing inoculum concentrations of $<80 \mathrm{pg}$ had $\mathrm{TAI}<20$ in a wheat crop, while most fields with pre-sowing Ggt concentrations

Table 1 Numbers of first (W1) or second wheat (W2) crops with pre-sowing inoculum concentrations below 6 or greater than 80 pg Gaeumannomyces graminis var. tritici (Ggt) DNA/g soil but take-all severity index (TAI) over 20, and crops with pre-sowing concentrations of at least $80 \mathrm{pg}$ Ggt DNA/g soil and TAI of less than 20 on 10 New Zealand farms (A-M).

\begin{tabular}{cccccccc}
\hline \multirow{2}{*}{ Farm } & Sequence & $\begin{array}{c}\text { Pre-sowing } \\
\text { Ggt<6 }\end{array}$ & $\begin{array}{c}\text { TAI } \\
>20\end{array}$ & $\begin{array}{c}\text { Pre-sowing } \\
\text { Ggt }<80\end{array}$ & TAI $>20$ & $\begin{array}{c}\text { Pre-sowing } \\
\text { Ggt }>80\end{array}$ & $\begin{array}{c}\text { TAI } \\
<20\end{array}$ \\
\hline A & W1 & 6 & 1 & 9 & 1 & 0 & - \\
& W2 & 0 & - & 0 & - & 1 & 0 \\
\hline C & W1 & 13 & 0 & 19 & 0 & 0 & - \\
& W2 & 4 & 2 & 8 & 3 & 2 & 1 \\
\hline E & W1 & 16 & 0 & 18 & 0 & 0 & - \\
\hline J & W1 & 5 & 0 & 9 & 0 & 0 & - \\
\hline D & W1 & 0 & - & 2 & 2 & 0 & - \\
& W2 & 1 & 0 & 4 & 1 & 5 & 0 \\
\hline H & W1 & 7 & 0 & 14 & 1 & 0 & - \\
& W2 & 3 & 0 & 8 & 1 & 5 & 0 \\
\hline I & W1 & 3 & 1 & 10 & 3 & 4 & 4 \\
& W2 & 0 & - & 1 & 1 & 0 & - \\
\hline L & W1 & 9 & 0 & 18 & 0 & 0 & - \\
& W2 & 5 & 0 & 7 & 0 & 5 & 1 \\
\hline M & W1 & 3 & 0 & 20 & 0 & 2 & 2 \\
& W2 & 1 & 0 & 6 & 2 & 8 & 0 \\
\hline B & W1 & 2 & 0 & 9 & 0 & 1 & 1 \\
& W2 & 4 & 0 & 7 & 2 & 1 & 1 \\
\hline Total & W1 & 64 & 2 & 128 & 7 & 7 & 7 \\
& W2 & 18 & 2 & 41 & 10 & 27 & 3 \\
\hline
\end{tabular}

${ }^{1} \mathrm{~W} 1=$ wheat sown after a break crop, W2 = wheat sown after a first host crop. 
of $>80 \mathrm{pg}$ had TAI $>20$ in wheat. Overall, $5 \%$ of wheat crops sown into Ggt concentrations $<6 \mathrm{pg}$ had a TAI $>20$. Amongst second wheat crops, $11 \%$ and $24 \%$ with pre-sowing Ggt concentrations of $<6$ and $<80$ pg respectively, had a TAI $>20$. Of the second wheat crops with pre-sowing Ggt concentrations $>80 \mathrm{pg}$, only $11 \%$ had a $\mathrm{TAI}<20$. The different crop rotations for each farm influenced the amounts of take-all and soil Ggt concentrations in wheat crops. Defining features of each farm are described below.

\section{Farm A}

Forty-one percent of crops were hosts (Figure 1), of which $22 \%$ were wheat and usually the first host crop in the rotation. Ryegrass was a common break crop and often followed by peas. Inoculum concentrations following a break crop were usually low (Figure 2) but increased rapidly (to median 533 pg) during a host crop sequence. The median concentrations, across the 10 fields, were highest following a second or third host crop. Two of the 10 wheat crops in the monitored fields had a TAI $>20$, one followed a barley crop and had a pre-sowing Ggt concentration of $140 \mathrm{pg}$. The other followed a pea crop and had a pre-sowing Ggt concentration recorded at $1 \mathrm{pg}$.

\section{Farm C}

Most of the crops were hosts, mainly wheat (Figure 1). Wheat was frequently grown as a second host crop. The farm had a wide variety of break crops, clover being the most common. Inoculum concentrations were usually low after a break crop and often low after the first host crop (Figure 2). However, one-third of fields following a first host crop had concentrations of Ggt $>80 \mathrm{pg}$. Second wheat crops with pre-sowing inoculum concentrations of $G g t<80$ pg had a TAI $>20$ in $37 \%$ of fields.

\section{Farm E}

Thirty-five percent of crops were hosts (Figure 1 ), most of which were wheat and a few were barley. Wheat was sown only after a break crop, which was mostly ryegrass. Concentrations after a first wheat crop were usually low; only two of the 19 had Ggt>80 pg (Figure 3). Soil Ggt concentrations were almost always very low after a break crop (Figure 2).

\section{Farm J}

Thirty-five percent of crops were hosts (wheat, barley, rye or triticale). Ryegrass, then borage, were the most common break crops. Pre-sowing Ggt concentrations in the nine wheat crops monitored ranged from $0 \mathrm{pg}$ to $59 \mathrm{pg}$, and only two had Ggt>20 pg (Figure 3). Take-all was barely detectable in the crops. Postharvest Ggt concentrations after first host crops were often high, with seven of the 11 crops having Ggt>80 pg. Soil Ggt concentrations in the two rye crops that followed wheat on this farm were the highest recorded in the survey.

\section{Farm D}

Sixty-five percent of crops were hosts; many were barley or wheat crops following barley. Twentyfour percent of wheat crops were sown after a break crop (mostly ryegrass), the rest being sown after wheat or barley. Inoculum concentrations after a first, second or third host crop were amongst the highest of the farms studied, although they were not particularly high after a break crop (Table 1). Take-all was common. Eleven of the 14 wheat crops had TAI $>20$ (Table $1)$. In most cases, second wheat crops with presowing inoculum concentrations $G g t<80 \mathrm{pg}$ had a $\mathrm{TAI}<20$, while most with pre-sowing concentrations $G g t>80 \mathrm{pg}$ had a TAI $>20$.

\section{Farm H}

Host crops were grown intensively. There were relatively few first wheat crops, and as many as eight consecutive host crops. Ryegrass was the most common break crop. Median Ggt concentrations reached a maximum after the second host crop (Figure 2). After a break crop, $47 \%$ of the host crops had an inoculum concentration of Ggt>6 pg, but none was above $80 \mathrm{pg}$. Forty percent of the first host crops had a post harvest concentration of Ggt $>80 \mathrm{pg}$ (Figure 3 ). Seven percent of first wheat crops had a TAI $>20$, compared with $54 \%$ of second wheat crops. Eighty-eight percent of second wheat 
a

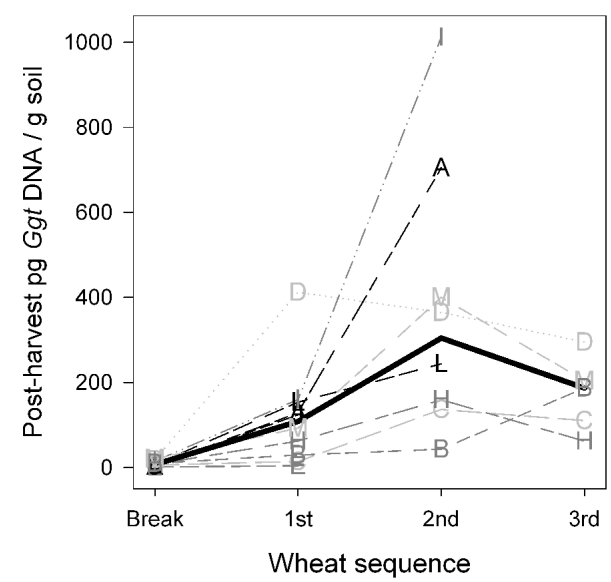

b

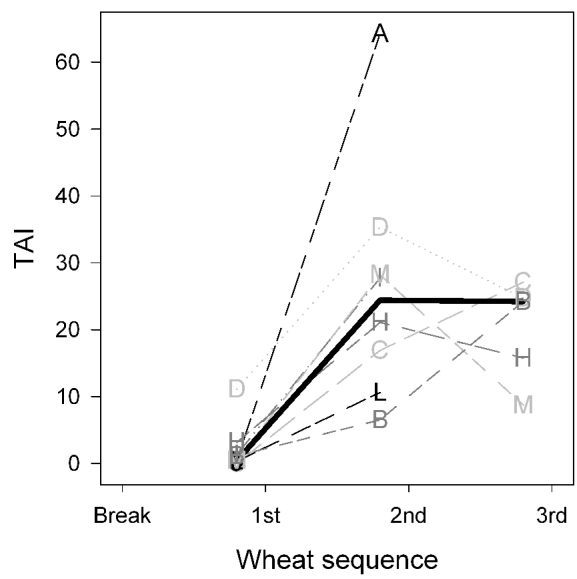

Figure 2 (a) Postharvest median inoculum concentrations (pg Gaeumannomyces graminis var. tritici $(G g t)$ DNA/g soil) and (b) take-all index (TAI) in wheat crops at different stages in the cropping sequence on 10 New Zealand farms (A-M). Thick line is median of all farms.

crops, with pre-sowing inoculum concentrations of $G g t<80 \mathrm{pg}$, also had $\mathrm{TAI}<20$, while all with Ggt> 80 pg had a TAI $>20$.

There were two fields in which host crops were grown in most years and could potentially induce take-all decline. Field $\mathrm{H} 3$ was sown with a third wheat crop in 2003, followed by non-wheat host crops until 2007 and 2008, when wheat was again sown. The Ggt reading was very high $(1526 \mathrm{pg})$ in the first year of the study, although the TAI was low (10). In following years, the Ggt concentrations usually ranged between $13 \mathrm{pg}$ and $64 \mathrm{pg}$, although one reading of $780 \mathrm{pg}$ was recorded after a barley crop. Pre-sowing Ggtconcentrations were moderate (64 pg and $38 \mathrm{pg}$ ) and take-all was moderate in the final 2 years. Conversely, field $\mathrm{H} 7$ had a history of severe take-all, even in fourth to sixth wheat crops.

\section{Farm I}

Host crops comprised $51 \%$ of the rotations; a third of these being barley, triticale or rye. A wide range of break crops was sown including ryegrass, pulses, brassicas and borage. Farm I had the highest proportion of those surveyed (29\%) of first host crops with pre-sowing Ggt concentrations of $>80 \mathrm{pg}$, and the second highest proportion of first wheat crops with a TAI $>20$ (Figure 3 ). It also had the highest proportion of fields with postharvest Ggt concentrations $>80 \mathrm{pg}$ following a first host crop.

\section{Farm L}

Approximately half the crops were host crops, mostly wheat. First-wheat crops made up twothirds of the crops, and second wheat crops one-third of wheat crops. Ryegrass was the most common break crop. This farm had the lowest median post-break Ggt concentration, and the lowest inoculum concentrations following a second host crop (Figure 2). Median TAI was one of the lowest in second wheat crops (Figure 2 ). No first wheat crops, and most second wheat crops, had a TAI $<20$. The TAI was proportional to the pre-sowing inoculum concentrations.

\section{Farm M}

This farm had the highest intensity of host crops (76\% of all crops), mostly wheat. One-third of wheat crops were first wheat crops and $21 \%$ were second wheat crops (Figure 1). The most common break crop was white clover. There was a single break crop between host crops. Despite the paucity of break crops, Ggt $>80$ pg was recorded 
a. Pre-sowing inoculum

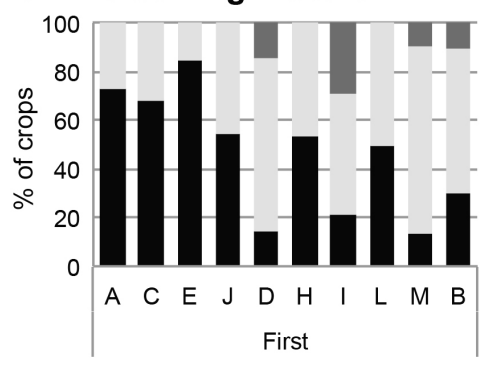

C. Take-all severity

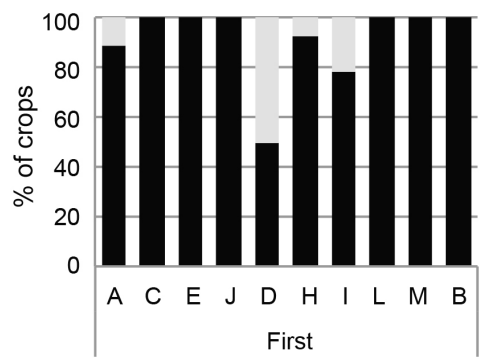

e. Post-harvest inoculum

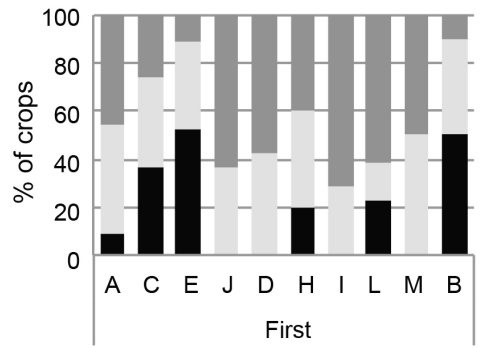

b.

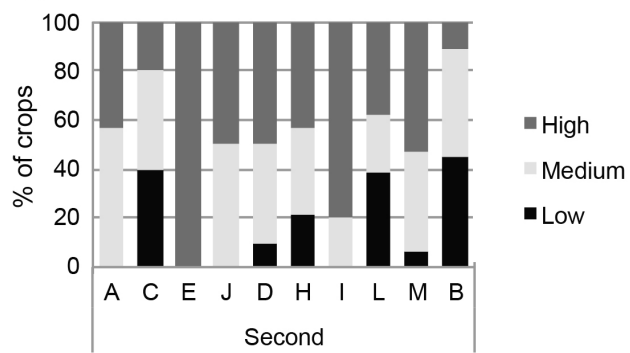

d.

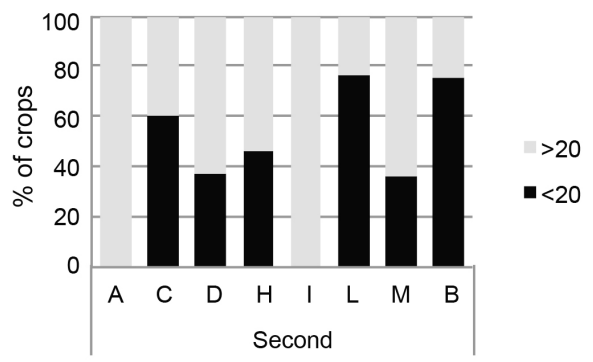

f.

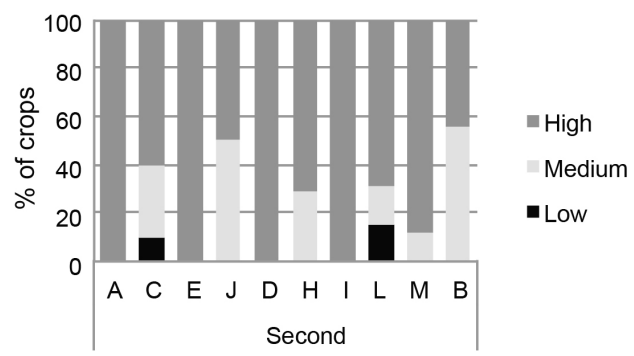

Figure 3 Proportions of fields where ( $\& \mathrm{~b}$ ) pre-sowing and (e \& f) postharvest inoculum concentrations (pg Gaeumannomyces graminis var. tritici (Ggt) DNA) were below 6 (Low), between 6-80 (Medium) or above $80 \mathrm{pg}$ Ggt DNA/g soil (High), and (c \& d) proportions of wheat crops with take-all severity index (TAI) greater than 20 in fields on 10 New Zealand farms (A-M) where a first (a, c \& e) or second (b, d \& f) host crop was sown.

in only $9 \%$ of fields prior to sowing a first host crop (Figure 3). Median Ggt concentrations after a first host crop were higher than on most other farms and median TAI in second wheat crops was also high. Of the 14 second wheat crops, nine had TAI $>20$, eight of which had pre-sowing $G g t>80 \mathrm{pg}$. Of the five second wheat crops with Ggt $<80 \mathrm{pg}$, four had TAI $<20$ (Figure 3).

\section{Farm B}

The only farm in the study from Southland, this had $74 \%$ of crops, mostly wheat and barley, as hosts of Ggt, including several long-term cereal fields. Break crops were usually sown for only 1 year. While oat crops were regularly sown, G. graminis var. avenae ( $G g a$ - which is pathogenic on oats as well as wheat) was not 
common. Ggt concentrations after oats were similar to those following other break crops but on one occasion, Ggt concentration after oats was high (185 pg in field B7) and Gga was also detected intermittently. Ggt concentrations were similar to those on other farms, despite the low numbers of break crops. Take-all severity in first wheat crops was low; none had a TAI $>20$ (Figure 3 ). Take-all severity was also low in second wheat crops, with TAI $>20$ being recorded in only $25 \%$ of crops. One field was sown continuously with wheat for 9 years and had TAI $>20$ in 5 of 6 six years in which it was assessed (fourth to ninth wheat crops); the $\mathrm{TAI}<20$ was recorded in the second last year of the study.

\section{DISCUSSION}

There was a wide variation in crop rotations and take-all severity in wheat crops across the 10 farms in this study. Ggt was detected on all farms, demonstrating its ubiquity in New Zealand cropping soils. Take-all and Ggt concentrations varied greatly during the different crop rotations adopted on the farms. Other factors, such as irrigation, dryland cropping and numbers of volunteer hosts in break crops are likely to explain some of the differences among farms.

The various crop rotation strategies used on farms, and their effects on Ggt and takeall in fields with less than $6 \mathrm{pg}$ or more than $80 \mathrm{pg}$, are examined below. Fields with these concentrations have been shown to correspond to low and high risk of take-all in second wheat crops, while above-ground take-all symptoms are most common where the take-all index (TAI) is over 20 (Bithell et al. 2012).

\section{Proportion of host crops in the rotation}

Maintaining a low proportion of hosts in the sequence of crops decreases both inoculum and disease. For the three farms (A, E and J) that had less than $40 \%$ host crops planted, E and J never had a TAI $>20$ recorded in their wheat crops. Farm E had some of the lowest Ggt concentrations after a break crop, which continued on to low concentrations after most first wheat crops. However, in two of the 20 first wheat crops on
Farm E, post-harvest concentrations of Ggt in the soil were $>80 \mathrm{pg}$ and at risk of severe takeall, should second wheat crops be sown. This strategy was less effective on Farm A.

Growing a high proportion of host crops increases both inoculum and take-all disease, but is used on some farms because of the relatively high value of wheat compared with other cropping options. Farms D, N and B had more than $60 \%$ host crops in the rotation, with $\mathrm{D}$ having the highest proportion of wheat crops with a TAI $>20$.

\section{Break crops}

Non-host crops (e.g. brassicas, canola, pulses, ryegrass and clover) reduce Ggt inoculum concentrations and the risk of take-all in the following wheat crop. Oats are also a useful break crop if Gga is not present.

Longer breaks (e.g. two successive non-host crops) produced more consistent reductions in Ggt concentrations and lower take-all risk than a shorter single break. Over all farms in 2003, a median of 33 pg followed a single break, compared with $1 \mathrm{pg}$ following a double break. In 2004, the median TAI in second wheat crops following a single break was 20 pg compared with $5 \mathrm{pg}$ in fields which had a double break of two non-host crops.

Prairie grass cannot be regarded as a break crop as it has been shown to host Ggt, resulting in very high Ggt concentrations in field trials (Bithell et al. 2011). This effect was seen on Farm E, where the second highest Ggt concentration of the study was recorded in a field after 2 years in prairie grass.

\section{Position of wheat in the host crop sequence}

The risk of take-all is lower in wheat at the start of a host crop sequence as inoculum concentrations can build up in first year wheat to infect second wheat crops. This was shown on Farm A where the rapid increase in inoculum concentrations during first wheat crops on Farm A led to the severe take-all on the only occasion a second wheat crop was sown.

The greater the proportion of fields with second wheat crops, the greater the overall loss 
to take-all is likely to be. The risk of take-all in wheat is as great if wheat is sown after barley, triticale or rye as is if sown after wheat, as shown on Farm D, where growing wheat after barley probably contributed to the take-all in wheat. General avoidance of second wheat crops is a sensible strategy for the control of take-all.

Although susceptible to take-all, barley is generally considered to suffer lower yield loss than wheat (Scott 1981). Triticale and rye are cereals less susceptible to Ggt than wheat so, along with barley, are safer second host crop options. Barley or rye crops were sometimes sown after first wheat crops on Farm B and also on Farm J where second wheat crops were never sown. This, along with the relatively low proportion of host crops, resulted in no wheat crops with TAI $>20$. Barley and rye have, however, been shown in field experiments in New Zealand to lead to Ggt concentrations as high, or higher, than after wheat (Bithell et al. 2011). Two of the highest Ggt concentrations on Farm J were recorded after the two rye crops.

\section{Take-all suppression}

Growing continuous wheat can lead to development of take-all decline, but at least one crop is usually severely infected before disease suppression becomes evident. Take-all decline may have developed in field $\mathrm{H} 3$ on Farm H. This field had a high frequency of host crops, with the Ggt concentration being very high $(1,526 \mathrm{pg})$ in the first year (although the TAI was only 10) but lower in the following years, with concentrations usually varying between 13 pg and 64 pg. Chng (2009) demonstrated that soil was suppressive to takeall in growth chamber experiments. However, the development of take-all decline is not reliable. For instance, in a second continuously cropped field, $\mathrm{H} 7$, severe take-all was still observed in the fourth to sixth successive wheat crops but Chng (2009) found no evidence of biologically mediated takeall decline in that soil.

\section{Strategies to assess take-all risk}

Soil tests for Ggt can be used to predict the risk of severe take-all (Bithell et al. 2012), but may predict take-all risk better on some farms than others. On Farms D, L and M, pre-sowing Ggt concentrations identified all high risk fields, most of which had been sown to one or more successive host crops. Some continuous cereal fields had relatively low Ggt concentrations, e.g. four of six second wheat crops on Farm M had Ggt<80 pg, resulting in $\mathrm{TAI}<20$, so there is scope to reduce take-all in fields sown to successive cereals by selecting those with low Ggt concentrations.

Take-all history can be used to plan cropping sequences. Ggt multiplication and take-all severity in second wheat crops varied among farms. On some farms (e.g. A and I), Ggt concentrations after the first host crop were always high, so avoiding second wheat crops would be desirable. Farm B had the lowest proportion of fields with a Ggt concentration $>80$ pg after a first host crop, so second-wheat crops would be possible in that situation. Irrigated farms tended to have more severe take-all in second wheat crops than dryland farms, suggesting that a focus on inoculum minimisation will be particularly important in irrigated fields.

\section{ACKNOWLEDGEMENTS}

We thank the farmers who gave access to their fields and field management information for this study. We also thank Ina Dumitrescu, Russell Burns and Aidan Thomson at SARDI for processing the samples, Ruth Butler of Plant \& Food Research for the graphs. The research was funded by a Ministry of Science and Innovation contract (LINX0804) and the Ministry for Primary Industries Sustainable Farming Fund.

\section{REFERENCES}

Bailey DJ, Gilligan CA 1999. Dynamics of primary and secondary infection in take-all epidemics. Phytopathology 89: 84-91.

Bateman GL, Gutteridge RJ, Jenkyn JF 2004. Take-all and grain yields in sequences of winter wheat crops testing fluquinconazole seed treatment applied in different combinations of years. Annals of Applied Biology 145: 317-330. 
Bithell SL, Butler RC, Harrow S, McKay A, Cromey MG 2011. Susceptibility to take-all of cereal and grass species, and their effects on pathogen inoculum. Annals of Applied Biology 159: 252-266.

Bithell SL, McKay A, Butler RC, Herdina, Ophel-Keller K, Hartley D, Cromey MG 2012. Predicting take-all severity in secondyear wheat using soil DNA concentrations of Gaeumannomyces graminis var. tritici determined with qPCR. Plant Disease 96: 443-451.

Bithell SL, McLachlan ARG, Hide CCL, McKay A, Cromey MG 2009. Changes in post-harvest levels of Gaeumannomyces graminis var. tritici inoculum in wheat fields. Australasian Plant Pathology 38: 277-283.

Chng SF 2009. Microbial factors associated with the natural suppression of take-all in wheat in New Zealand. PhD thesis, Lincoln University, Canterbury, New Zealand.

Cook RJ 2003. Take-all of wheat. Physiological and Molecular Plant Pathology 62: 73-86.

Cromey MG, Parkes RA, Fraser PM 2006. Factors associated with stem base and root diseases of New Zealand wheat and barley crops. Australasian Plant Pathology 35: 1-10.
Hornby D 1981. Inoculum. In: Asher MJC, Shipton PJ ed. Biology and Control of Takeall. Academic Press Inc. London Ltd, London, UK. Pp. 271-293.

Hornby D 1998. Take-all Disease of Cereals: A Regional Perspective. CAB International, Wallingford, UK.

Hornby D, Beale R 2000. Take-all Management Guide. Monsanto Plc, Agricultural Sector, Maris Lane, Trumpington, Cambridge, UK.

MacNish GC, Dodman RL 1973. Survival of Gaeumannomyces graminis var. tritici in the field. Australian Journal of Biological Sciences 26: 1309-1317.

Ophel-Keller K, McKay A, Hartley D, Herdina, Curran J 2008. Development of a routine DNA-based testing service for soilborne diseases in Australia. Australasian Plant Pathology 37: 243-253.

Scott PR 1981. Variation in host susceptibility. In: Asher MJC, Shipton PJ ed. Biology and Control of Take-All. Academic Press Inc. London Ltd., London, UK. Pp. 219-236.

Yarham DJ 1981. Practical aspects of epidemiology and control. In: Asher MJC, Shipton PJ ed. Biology and Control of Takeall. Academic Press Inc. London Ltd, London, UK. Pp. 353-384. 